University of Nebraska - Lincoln

DigitalCommons@University of Nebraska - Lincoln

\title{
Anaerobic Treatment of Army Ammunition Production Wastewater Containing Perchlorate and RDX
}

\author{
Emina Atikovic \\ Department of Civil and Environmental Engineering, University of Cincinnati, Cincinnati, $\mathrm{OH} 45221$, United \\ States \\ Makram T. Suidan \\ Department of Civil and Environmental Engineering, University of Cincinnati, Cincinnati, $\mathrm{OH} 45221$, United \\ States \\ Stephen W. Maloney \\ US Army Construction Engineering Research Laboratory, Champaign, IL 61826-9005, United States
}

Follow this and additional works at: https://digitalcommons.unl.edu/usarmyresearch

Part of the Operations Research, Systems Engineering and Industrial Engineering Commons

Atikovic, Emina; Suidan, Makram T.; and Maloney, Stephen W., "Anaerobic Treatment of Army Ammunition Production Wastewater Containing Perchlorate and RDX" (2008). US Army Research. 40.

https://digitalcommons.unl.edu/usarmyresearch/40

This Article is brought to you for free and open access by the U.S. Department of Defense at DigitalCommons@University of Nebraska - Lincoln. It has been accepted for inclusion in US Army Research by an authorized administrator of DigitalCommons@University of Nebraska - Lincoln. 


\title{
Anaerobic treatment of army ammunition production wastewater containing perchlorate and RDX
}

\author{
Emina Atikovic ${ }^{\mathrm{a}}$, Makram T. Suidan ${ }^{\mathrm{a}, *}$, Stephen W. Maloney ${ }^{\mathrm{b}}$ \\ a Department of Civil and Environmental Engineering, University of Cincinnati, Cincinnati, OH 45221, United States \\ ${ }^{\mathrm{b}}$ US Army Construction Engineering Research Laboratory, Champaign, IL 61826-9005, United States
}

\section{A R T I C L E I N F O}

\section{Article history:}

Received 12 November 2007

Received in revised form 16 May 2008

Accepted 19 May 2008

Available online 30 June 2008

\section{Keywords:}

Perchlorate

RDX

Anaerobic

Fluidized bed

\begin{abstract}
A B S T R A C T
Perchlorate is an oxidizer that has been routinely used in solid rocket motors by the Department of Defense and National Aeronautics and Space Administration. Royal Demolition Explosive (RDX) is a major component of military high explosives and is used in a wide variety of munitions. Perchlorate bearing wastewater typically results from production of solid rocket motors, while RDX is transferred to Army industrial wastewaters during load, assemble and pack operations for new munitions, and hot water or steam washout for disposal and deactivation of old munitions (commonly referred to as demilitarization, or simply demil).

Biological degradation in Anaerobic Fluidized Bed Reactors (AFBR), has been shown to be an effective method for the removal of both perchlorate and RDX in contaminated wastewater. The focus of this study was to determine the effectiveness of removal of perchlorate and RDX, individually and when co-mingled, using ethanol as an electron donor under steady state conditions. Three AFBRs were used to assess the effectiveness of this process in treating the wastewater. The performance of the bioreactors was monitored relative to perchlorate, RDX, and chemical oxygen demand removal effectiveness. The experimental results demonstrated that the biodegradation of perchlorate and RDX was more effective in bioreactors receiving the single contaminant than in the bioreactor where both contaminants were fed.
\end{abstract} (c) 2008 Elsevier Ltd. All rights reserved.

\section{Introduction}

Production and handling of a high explosive mixture generates wastewater contaminated with energetic compounds such as perchlorate and Royal Demolition Explosive (RDX). A major source of perchlorate contamination comes from ammonium perchlorate, which is used as an oxidizer component and primary ingredient in solid propellants for rockets, missiles, and fireworks. Perchlorate has been routinely used in solid rocket motors by the Department of Defense (DoD) and National Aeronautics and Space Administration (NASA). One of the advantages of perchlorate is that it is easily washed out of old rocket motors and can be crystallized for reuse in civilian applications such as commercial fireworks and road flares. The washout operation, however, generates wastewaters containing perchlorate that can persist in the environment for decades (Urbansky, 2000) due to its poor-reactivity and high water solubility.

RDX, also known as hexahydro-1,3,5-trinitro-1,3,5-triazineor, is a major component of military high explosives and is used in a wide variety of munitions. RDX is a white solid made of orthorhombic colorless crystals that are chemically and thermally very

\footnotetext{
* Corresponding author. Tel.: +1 513556 3695; fax: +1 5135562599.

E-mail addresses: atikovic@gmail.com (E. Atikovic), makram.suidan@uc.edu (M.T. Suidan), s-maloney@cecer.army.mil (S.W. Maloney).
}

stable and are soluble in certain organic solvents but not in water (Luca et al., 1999). Due to its stability, RDX is widely used in various military and civilian applications. RDX is transferred to Army industrial wastewaters during the load, assemble and pack operations for new munitions, and hot water or steam washout for disposal and deactivation of old munitions (commonly referred to as demilitarization, or simply demil). Manufacturing, use, and destruction of explosive compounds can lead to discharge of highly toxic material into the environment (Aken et al., 2004). Because of its harmful effects, USEPA placed RDX on the priority pollutant list. Old disposal practices for both RDX and perchlorate have led to groundwater contaminated by both compounds, but they have not been commingled in wastewater in the past.

Conventional munitions used by the DoD since II have suffered from problems associated with unwanted detonations that occur when munitions are heated or struck by debris from adjacent explosions. An example of such an occurrence is the explosion on the U.S.S. Forrestal which nearly sank during the Vietnam War when a plane crashed on landing, causing other munitions stored on board to detonate. This and other similar incidences lead to the development of munitions that are less sensitive than those currently employed.

A combination of perchlorate and RDX, with or without other ingredients, presents a potential candidate for a less sensitive munition. However, existing Army ammunition plants do not have 
unit operations in their industrial treatment facilities to remove perchlorate from wastewater. A commonly applied process, adsorption onto activated carbon, is expected to be ineffective against perchlorate, due to the polarity and high water solubility of perchlorate (Parette et al., 2005).

The Anaerobic Fluidized Bed Reactor (AFBR) has been evaluated over the past 10 years for the treatment of energetic contaminants (VanderLoop et al., 1998; Maloney et al., 2002; USDD, 2003; Adrian and Arnett, 2004). Application of this process to the treatment of munitions laden wastewaters has typically involved the addition of ethanol as a co-substrate to assist in the establishment of the redox conditions needed for the reduction of the nitro groups to amines. These transformed compounds can then be degraded aerobically. The AFBR has been successfully employed for the pretreatment of pinkwater prior to discharge to an existing industrial water treatment facility at an Army ammunition plant (USDD, 2003).

The AFBR has also been used for the treatment of perchlorate (Fuller et al., 2007). In that work, it was determined that perchlorate served as an electron acceptor at redox conditions lower than those required for nitrate reduction, but higher than those needed for sulfate reduction. This process has been applied for the remediation of several groundwater sites contaminated with perchlorate (Veenstra et al., 2003; Fuller et al., 2007). However, the level of groundwater contamination is usually at low concentrations $\left(<5 \mathrm{mg} \mathrm{l}^{-1}\right)$ compared to the concentrations expected from wastewaters emanating from munitions production facilities $\left(>100 \mathrm{mg} \mathrm{l}^{-1}\right)$. Furthermore, prior research has shown that the redox levels lower than $-200 \mathrm{mV}$ are needed for the reduction of trinitro toluene (Lewis et al., 1977; Simplot, 1995). The presence of an oxidizer such as perchlorate is expected to affect redox conditions and may, therefore, interfere with the effectiveness of the AFBR in treating wastewaters containing energetic compounds commingled with perchlorate.

The research presented in this manuscript represents an assessment of the effectiveness of the AFBR in treating wastewaters containing perchlorate and RDX individually and when commingled. Sand was utilized as the microbial attachment medium instead of the commonly used granular activated carbon in order to separate the role of adsorption from biotransformation.

\section{Materials and methods}

\subsection{Chemicals}

Sodium perchlorate was used as the feed perchlorate source (>99\% purity, Fisher Scientific Co., Pittsburgh, PA). RDX was supplied by the US Army Engineering Research and Development Center-Construction Engineering Research Laboratory. Ethanol was obtained from University of Cincinnati Chemical Stores (200 proof). All other chemicals used in this study were of 95\% purity or greater and were purchased from Fisher Scientific Co., Pittsburgh, PA.

\subsection{Design and operation of the AFBRs}

Three 9.1 l AFBR were used for this study. Bioreactor-P was used to evaluate the effectiveness of reducing perchlorate with ethanol as an electron donor, bioreactor- $\mathrm{R}$ was used to determine the reduction of RDX under the same electron donor conditions, and bioreactor-P\&R was set up to examine the simultaneous treatment of both perchlorate and RDX in the same reactor. Each bioreactor consisted of a jacketed main column and influent and effluent headers. The inner tube $(96.5 \mathrm{~cm}$ long, $10.2 \mathrm{~cm}$ inner diameter) was constructed of Plexiglas and was enclosed in an outer jacket also constructed from a Plexiglas tube. Water was circulated through the annular space between the two tubes of the AFBRs from a constant temperature bath (Model 28M-L Fisher Scientific Isotemp Water bath, Pittsburgh, PA) to maintain a constant temperature of $35^{\circ} \mathrm{C}$ within the columns. The recycle lines were constructed of polyvinyl chloride tubing while the feed and effluent lines were Tygon and neoprene tubing.

Each AFBR was charged with $2.0 \mathrm{~kg}$ of $20 \times 30$ US Mesh $(0.59-0.84 \mathrm{~mm})$ silica sand serving as the attachment medium. The influent header of each bioreactor was filled with marbles, which distributed the flow evenly across the column cross section. The effluent header captured gas produced during the treatment process, and allowed the liquid effluent to exit the AFBR. The wastewater fed to the AFBRs consisted of a mixture of three streams: an acidified nutrient stream containing salts and vitamins; a buffer stream containing the phosphate, sulfide and sodium carbonate; and a stream containing the contaminants (perchlorate and/or RDX) and ethanol (Atikovic, 2006). These streams were fed into the recycle line using $2 \mathrm{rpm}$ Masterflex pumps (Cole-Palmer, Chicago, IL) to provide a total flow rate of $6 \mathrm{ld}^{-1}$. The AFBRs were operated under strict methanogenic conditions with no added electron acceptors such as $\mathrm{SO}_{4}$ or $\mathrm{NO}_{3}$.

The concentrations of ethanol in the feed to each bioreactor are presented in Tables 1-3. These concentrations were varied at different stages of the operation in order to determine the minimum concentration of this electron donor that would affect contaminant transformation. The stoichiometric concentration of ethanol needed for reduction of perchlorate and RDX are 37 for Bioreactor-P, 2 initially for Bioreactor-R and $39 \mathrm{mg} \mathrm{l}^{-1}$ initially for Bioreactor-P\&R (Atikovic, 2006). During the course of the study, the influent RDX concentration was changed from 20 to $10 \mathrm{mg} \mathrm{l}^{-1}$, yielding a reduction in the stoichiometric requirements for ethanol to $1 \mathrm{mg} \mathrm{l}^{-1}$ for Bioreactor-R, and $38 \mathrm{mg} \mathrm{l}^{-1}$ for Bioreactor-P\&R. This reduction in the influent RDX concentration was carried out in an attempt to determine the highest influent concentration of this contaminant that would yield acceptable effluent quality.

The AFBRs were operated for 1.5 years with the concentrations of perchlorate and RDX in the final feed of 120 and $0 \mathrm{mg} \mathrm{l}^{-1}$ to bioreactor-P; 0 and $20 \mathrm{mg} \mathrm{l}^{-1}$ to bioreactor-R and 120 and $20 \mathrm{mg} \mathrm{l}^{-1}$ to bioreactor-P\&R. The concentration of RDX in bioreactor-R and bioreactor-P\&R was decreased to $10 \mathrm{mg} \mathrm{l}^{-1}$ later in the study (day 274). The $\mathrm{pH}$ of the bioreactors was maintained between 7.0 and 7.2 .

The AFBRs were seeded with $50 \mathrm{ml}$ of anaerobic digester sludge obtained from a pilot-scale system operated at the Environmental Engineering and Science laboratory of the University of Cincinnati.

Table 1

Bioreactor-P effluent quality data (average of all data)

\begin{tabular}{|c|c|c|c|c|}
\hline Period & Ethanol feed conc. (mg l-1) & $\mathrm{ClO}_{4}^{-}\left(\mathrm{mg} \mathrm{l}^{-1}\right)$ & $\operatorname{COD}\left(\mathrm{mg} \mathrm{l}^{-1}\right)$ & VFA $\left(\mathrm{mg} \mathrm{l}^{-1}\right)$ acetic acid \\
\hline $52-155$ & 185 & $0.02( \pm 0.01)$ & $14( \pm 8)$ & $1.6( \pm 0.5)$ \\
\hline $156-318$ & 93 & $0.01( \pm 0.01)$ & $14( \pm 6)$ & $0.03( \pm 0.1)$ \\
\hline \multicolumn{5}{|l|}{$333-384$} \\
\hline $319-332$ & 46 & $0.21( \pm 0.13)$ & $11( \pm 4)$ & $0.00( \pm 0.0)$ \\
\hline 385-532 & 69 & $0.00( \pm 0.00)$ & $11( \pm 6)$ & $1.0( \pm 1.5)$ \\
\hline
\end{tabular}


Table 2

Bioreactor-R effluent quality data (average of all data)

\begin{tabular}{|c|c|c|c|c|c|}
\hline \multirow[t]{2}{*}{ Period } & \multirow[t]{2}{*}{ Ethanol feed conc. $\left(\mathrm{mg} \mathrm{l}^{-1}\right)$} & \multirow[t]{2}{*}{$\operatorname{RDX}\left(\mathrm{mg} \mathrm{l}^{-1}\right)$} & \multirow[t]{2}{*}{$\operatorname{COD}\left(\mathrm{mg} \mathrm{l}^{-1}\right)$} & \multicolumn{2}{|l|}{$\operatorname{VFA}\left(\mathrm{mg} \mathrm{l}^{-1}\right)$} \\
\hline & & & & Acetic acid & Propionic acid \\
\hline $52-155$ & 100 & $0.20( \pm 0.15)$ & $88( \pm 15)$ & $41.7( \pm 3.8)$ & $27.0( \pm 3.4)$ \\
\hline $156-231$ & 50 & $0.17( \pm 0.06)$ & $42( \pm 19)$ & $19.7( \pm 5.3)$ & $9.1( \pm 3.7)$ \\
\hline $232-384$ & 150 & $0.13( \pm 0.22)$ & $62( \pm 26)$ & $37.9( \pm 17.2)$ & $16.3( \pm 9.7)$ \\
\hline $385-532$ & 200 & $0.00( \pm 0.00)$ & 14 ( \pm 8 Department of defense, Washington, DC) & $4.2( \pm 2.1)$ & $1.2( \pm 0.6)$ \\
\hline
\end{tabular}

Table 3

Bioreactor-P\&R Effluent Quality Data (average of all data)

\begin{tabular}{|c|c|c|c|c|c|c|}
\hline \multirow[t]{2}{*}{ Period } & \multirow[t]{2}{*}{ Ethanol feed conc. $\left(\mathrm{mg} \mathrm{l}^{-1}\right)$} & \multirow[t]{2}{*}{$\mathrm{ClO}_{4}^{-}\left(\mathrm{mg} \mathrm{l}^{-1}\right)$} & \multirow[t]{2}{*}{$\mathrm{RDX}\left(\mathrm{mg} \mathrm{l}^{-1}\right)$} & \multirow[t]{2}{*}{$\mathrm{COD}\left(\mathrm{mg} \mathrm{l}^{-1}\right)$} & \multicolumn{2}{|l|}{$\mathrm{VFA}^{*}\left(\mathrm{mg} \mathrm{l}^{-1}\right)$} \\
\hline & & & & & Acetic acid & Propionic acid \\
\hline $52-155$ & 195 & $0.07( \pm 0.04)$ & $0.56( \pm 0.17)$ & $108( \pm 25)$ & $59.8( \pm 20.0)$ & $16.3( \pm 6.8)$ \\
\hline $156-318$ & 98 & $0.02( \pm 0.02)$ & $0.43( \pm 0.18)$ & $27( \pm 9)$ & $12.3( \pm 3.7)$ & - \\
\hline $319-384$ & 150 & $0.00( \pm 0.00)$ & $0.13( \pm 0.04)$ & $15( \pm 8)$ & $8.4( \pm 4.5)$ & $0.3( \pm 0.4)$ \\
\hline $385-414$ & 187 & $0.00( \pm 0.00)$ & $0.12( \pm 0.03)$ & $20( \pm 1)$ & $5.9( \pm 1.0)$ & $1.7( \pm 0.5)$ \\
\hline $415-447$ & 237 & $0.00( \pm 0.00)$ & $0.10( \pm 0.05)$ & $33( \pm 4)$ & $9.5( \pm 4.8)$ & $4.3( \pm 3.2)$ \\
\hline $448-471$ & 300 & $0.00( \pm 0.00)$ & $0.11( \pm 0.01)$ & $30( \pm 5)$ & $12.0( \pm 3.6)$ & $5.8( \pm 1.5)$ \\
\hline $472-532$ & 400 & $0.00( \pm 0.00)$ & $0.10( \pm 0.03)$ & $23( \pm 12)$ & $6.4( \pm 5.4)$ & $2.9( \pm 2.8)$ \\
\hline
\end{tabular}

$\mathrm{N}$-Butyric acid was detected in the effluent at an average concentration of $0.4( \pm 0.2)$ during the first operating period (day $52-155)$.

\subsection{Analytical methods}

Nutrient, buffer, and contaminants flow rates, $\mathrm{pH}$, temperature, and gas production were monitored on a daily basis. $\mathrm{pH}$ was measured using an Orion Model 720A pH meter (Orion Research Co., Boston, MA). Influent and Effluent chemical oxygen demand (COD), effluent volatile fatty acids (VFA), and gas production were monitored daily while gas composition was measured weekly. Gas samples from the AFBRs were analyzed using a Hewlett Packard 5890 Series II gas chromatograph (GC) (Hewlett Packard, Wilmington, Delaware) equipped with a thermal conductivity detector and a HP 3.05 m molecular sieve BX-45/60 mesh followed by a HP 1.83 m HAYESEP Q 80/100 column (SUPELCO, Bellefonte, PA). VFA were analyzed using an Agilent 6890 Series GC (Agilent Technologies, Palo Alto, California) equipped with flame ionization detector and $1.83 \mathrm{~m} \mathrm{80/120}$ Carbopack B-DA*/5\% Carbowax 20M packed column (SUPELCO, Bellefonte, PA).

Analyses of the influent and effluent for concentrations of perchlorate and RDX were performed three times a week. Perchlorate was analyzed using ion chromatography $\mathrm{dx} 500$ system (DIONEX Corporation, Sunnyvale, CA), with the anion guard column DIONEX AG $164 \mathrm{~mm}$, and anion separator column-DIONEX AS $164 \mathrm{~mm}$ (DIONEX Corporation, Sunnyvale, CA). The mobile phase consisted of $100 \% 50 \mathrm{mM}$ sodium hydroxide, at a flow rate of $1.5 \mathrm{ml} \mathrm{min}^{-1}$ (Hautman et al., 1999). The detection limit for perchlorate was determined to be $0.59 \mu \mathrm{g} \mathrm{l}^{-1}$. RDX was analyzed using a high performance liquid chromatograph 1100 series with diode array detector with absorbance set at $220 \mathrm{~nm}$ (Agilent Technologies, Palo Alto, California). The column used was ZORBAX SB-C18, $5 \mu \mathrm{m}$ $4.6 \times 250 \mathrm{~mm}$ (Agilent Technologies, Palo Alto, California). Water and methanol (60:40) were used as the mobile phase at a flow rate of $1.0 \mathrm{ml} \mathrm{min}{ }^{-1}$ (USEPA, 1994). The detection limit for RDX was $0.87 \mu \mathrm{g} \mathrm{l^{-1 }}$.

\section{Results and discussion}

\subsection{Reactor performance}

Tables $1-3$, respectively, summarize the performance of the three AFBRs for the entire experimental period of $532 \mathrm{~d}$. The three bioreactors were inoculated with a microbial culture obtained from a laboratory-scale sludge digester. On day 0 , perchlorate and RDX were introduced into the reactor feed at influent concen- trations of $120 \mathrm{mg} \mathrm{l}^{-1}$ perchlorate for Bioreactor-P and Bioreactor$P \& R$, and $20 \mathrm{mg} \mathrm{l}^{-1}$ RDX for Bioreactor-R and Bioreactor-P\&R. The influent concentration of RDX in Bioreactor-R and Bioreactor-P\&R was subsequently decreased to $10 \mathrm{mg} \mathrm{l}^{-1}$ on day 274 . The influent concentration of ethanol to the three bioreactors was initially set to $200 \mathrm{mg} \mathrm{l}^{-1}$. This was later varied on day 52 when influent ethanol concentrations of 185,100 , and $195 \mathrm{mg} \mathrm{l}^{-1}$ were set for Bioreactor-P, Bioreactor-R, and Bioreactor-P\&R, respectively. The influent concentrations of ethanol to Bioreactor-P and BioreactorP\&R were selected to correspond to fivefold the stoichiometric values needed for the reduction of the feed energetic compounds, while the feed concentration to Bioreactor- $\mathrm{R}$ was arbitrarily set to $100 \mathrm{mg} \mathrm{l}^{-1}$ since it is difficult to maintain an anaerobic system with $10 \mathrm{mg} \mathrm{l}^{-1}$ of ethanol (fivefold the stoichiometric concentration needed to reduce the influent concentration of RDX).

Average effluent COD concentrations and their standard deviations are presented in Tables 1-3 for Bioreactor-P, Bioreactor-R, and Bioreactor-P\&R. As these data illustrate, effluent concentrations of COD for all three bioreactors were independent of the concentration of electron donor in the feed. In fact, the effluent COD concentration was often observed to decrease with increasing concentrations of ethanol in the feed suggesting that better anaerobic activity may be sustained under higher loadings of electron donor. Furthermore, and because of the presence of the energetic compounds in the feed, it is expected that a minimum influent concentration of the electron donor is needed for proper methanogenic activity to prevail. This minimum concentration is a function of the presence of the energetic compound, the presence of dissolved oxygen in the feed, and the amount of oxygen that can diffuse into the reactor through Tygon tubing and the Plexiglas used in reactor construction. Scale-up of reactor size may mitigate some of these factors.

The average concentrations of VFA in the effluent from all three bioreactors are also shown in Tables 1-3 for Bioreactor-P, Bioreactor-R, and Bioreactor-P\&R, respectively. The effluent from bioreactor-P contained only acetic acid at concentrations averaging consistently below $2 \mathrm{mg} \mathrm{l}^{-1}$. Effluent from bioreactor-R contained both acetic and propionic acid at average concentrations ranging between 19 and $42 \mathrm{mg} \mathrm{l}^{-1}$ for acetic acid and 9 and $27 \mathrm{mg} \mathrm{l}^{-1}$ for propionic acid during the first three stages of operation shown in Table 2. During the fourth stage of operation, the effluent concentrations of acetic acid and propionic acid from this reactor averaged 4.2 and $1.3 \mathrm{mg} \mathrm{l}^{-1}$, respectively. This improvement in 
performance strongly correlates to the noticeable reduction in the effluent concentration of RDX for this period (discussed later). The effluent from Bioreactor-P\&R contained the three major VFA; acetic acid, propionic acid, and butyric acid (Cheng et al., 1996). The VFA data suggest no strong correlation between the VFA content of the reactor effluent and the influent concentration of electron donor. In fact, these data suggest that a minimum critical concentration of electron donor was needed to establish stable methanogenic conditions and that once these conditions are established, all three bioreactors affected good effluent quality relative to the concentration of VFAs.

\subsection{Perchlorate removal}

Figs. 1 and 2 show the performance of Bioreactor-P, which received perchlorate, and Bioreactor-P\&R, which received both perchlorate and RDX, relative to perchlorate removal. As seen from
Fig. 1 (perchlorate only), during the period between days 52 and 150 of perchlorate feeding, the concentration of this contaminant in the effluent from Bioreactor-P was variable, even through the operating conditions were maintained constant (steady influent concentrations of $120 \mathrm{mg} \mathrm{l}^{-1}$ ). During this period, the concentration of ethanol was five times the stoichiometric concentration needed to reduce the feed perchlorate. After day 156 , the effluent concentration of perchlorate stabilized at approximately $20 \mu \mathrm{g} \mathrm{l} \mathrm{l}^{-1}$.

At this point (day 156), the feed concentration of ethanol was reduced to 2.5 times the stoichiometric amount. This decrease in feed ethanol resulted in a temporary slight increase in the effluent concentration of perchlorate, which subsequently decreased to below the detection limit. Based on this behavior, the feed concentration of ethanol was further reduced to $46 \mathrm{mg} \mathrm{l}^{-1}$ (days 319-332), which is close to (1.25 times) its stoichiometric amount. This sharp decrease in the concentration of electron donor caused the

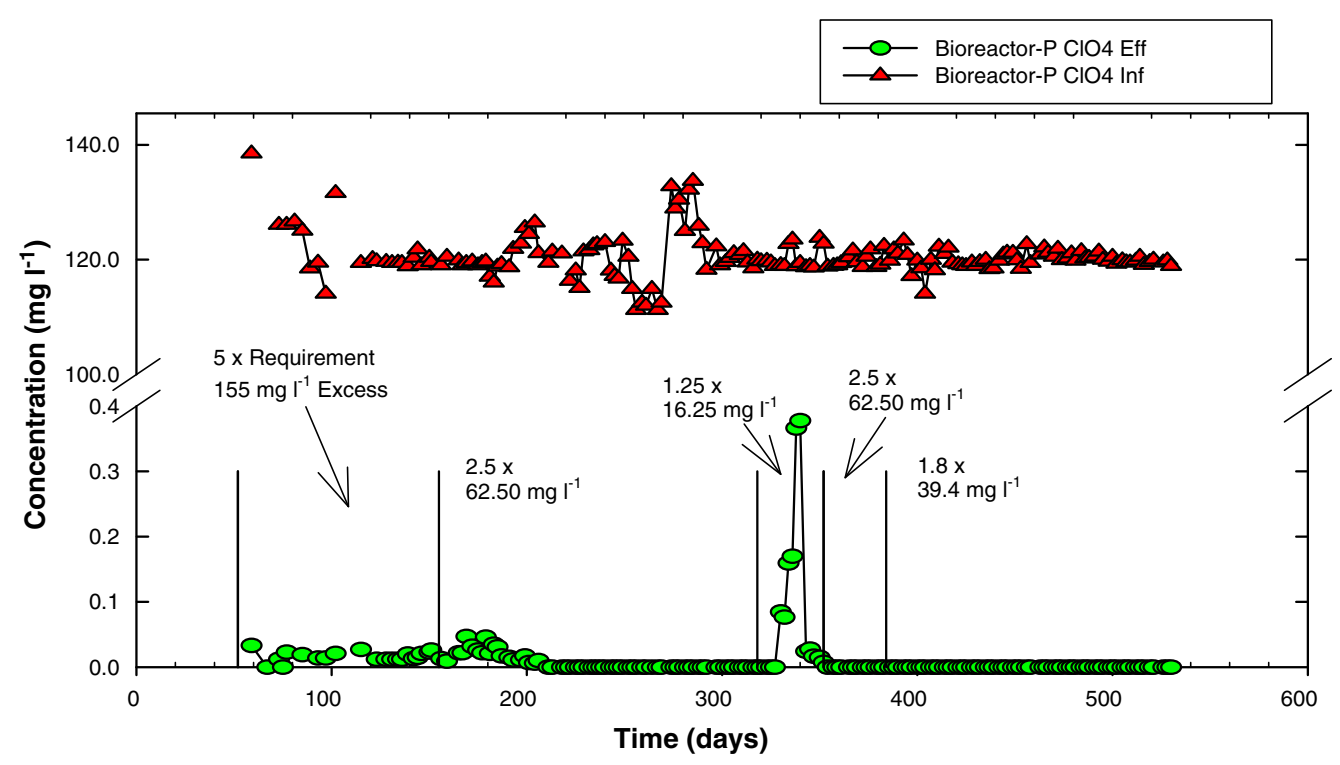

Fig. 1. Bioreactor-P perchlorate removal.

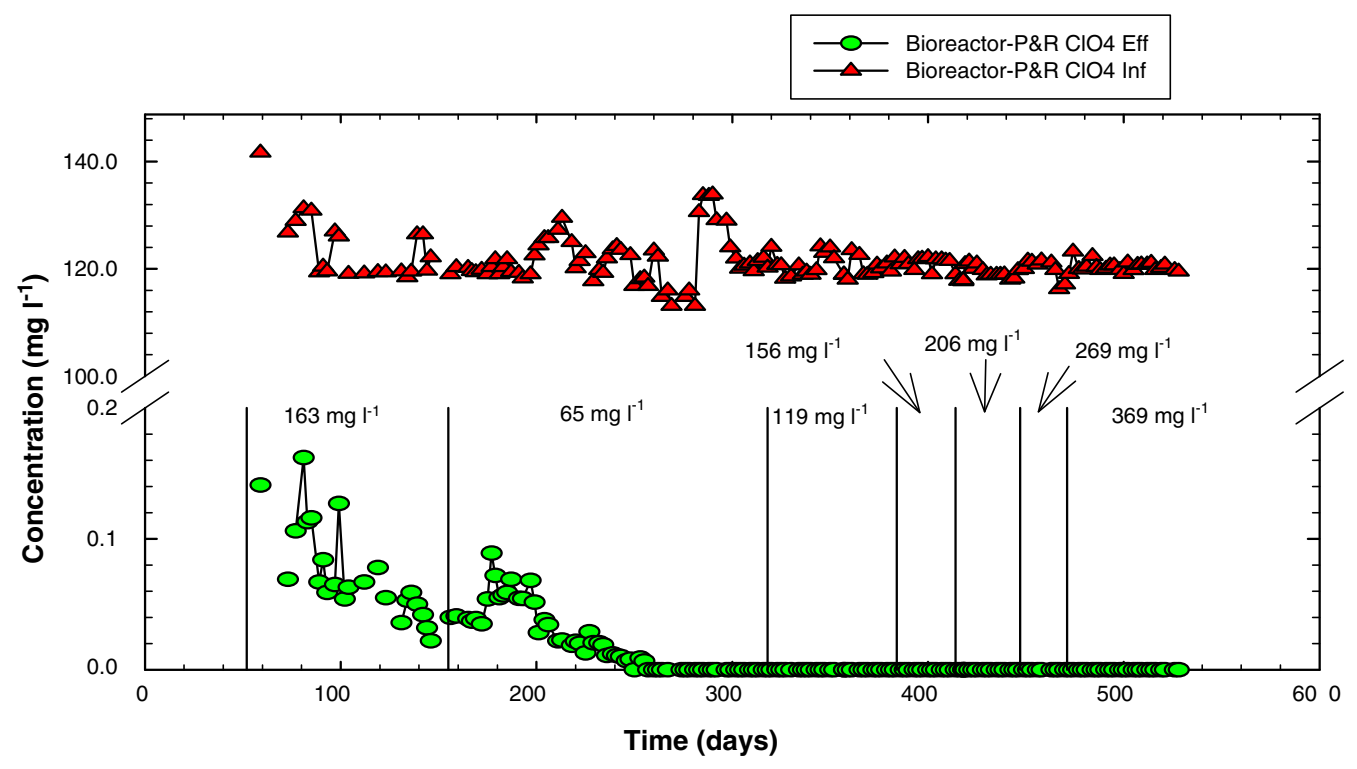

Fig. 2. Bioreactor-P\&R perchlorate removal. 
concentration of perchlorate in the effluent to increase from below the detection limit to over $400 \mu \mathrm{g} \mathrm{l} \mathrm{l}^{-1}$.

Due to this deterioration in reactor performance, the concentration of ethanol in the feed to Bioreactor-P was increased again to 2.5 times its stoichiometric amount. Recovery of the bioreactor was very rapid. The concentration of perchlorate in the final effluent decreased to below the detection limit within 2 wk of operation under the restored electron donor condition. Even when the concentration of ethanol was reduced to 1.8 times its stoichiometric demand (day 385) the effluent perchlorate concentration remained below the detection limit.

A somewhat different scenario was observed in Bioreactor-P\&R (Fig. 2). During the initial period of reactor operation, the concentration of ethanol in the feed was five times its stoichiometric amount, which resulted in a gradual decrease in effluent perchlorate concentration from 150 to approximately $70 \mu \mathrm{g} \mathrm{l} \mathrm{l}^{-1}$. After steady-state operation was attained (day 156), the concentration of ethanol was reduced to 2.5 times the stoichiometric amount. This reduction resulted in a small increase in effluent perchlorate concentration, which soon after decreased to below the detection limit.

The responses of Bioreactor-P and Bioreactor-P\&R to various concentrations of ethanol suggest that the efficiency of perchlorate reduction is not very sensitive to the influent concentration of electron donor, provided that concentration exceeds the stoichiometric demand of the energetic compounds present in the feed as well as the demand for electron donor needed to reduce any oxygen entering the anaerobic bioreactors. Figs. 1 and 2 show the excess amounts of electron donor (ethanol) as multiples of the stoichiometric requirement, as well as the excess ethanol in $\mathrm{mg} \mathrm{l}^{-1}$.

\section{3. $R D X$ removal}

Figs. 3 and 4 present the concentration of RDX in the influent and effluent of Bioreactor-R and P\&R. As can be seen from Fig. 3,

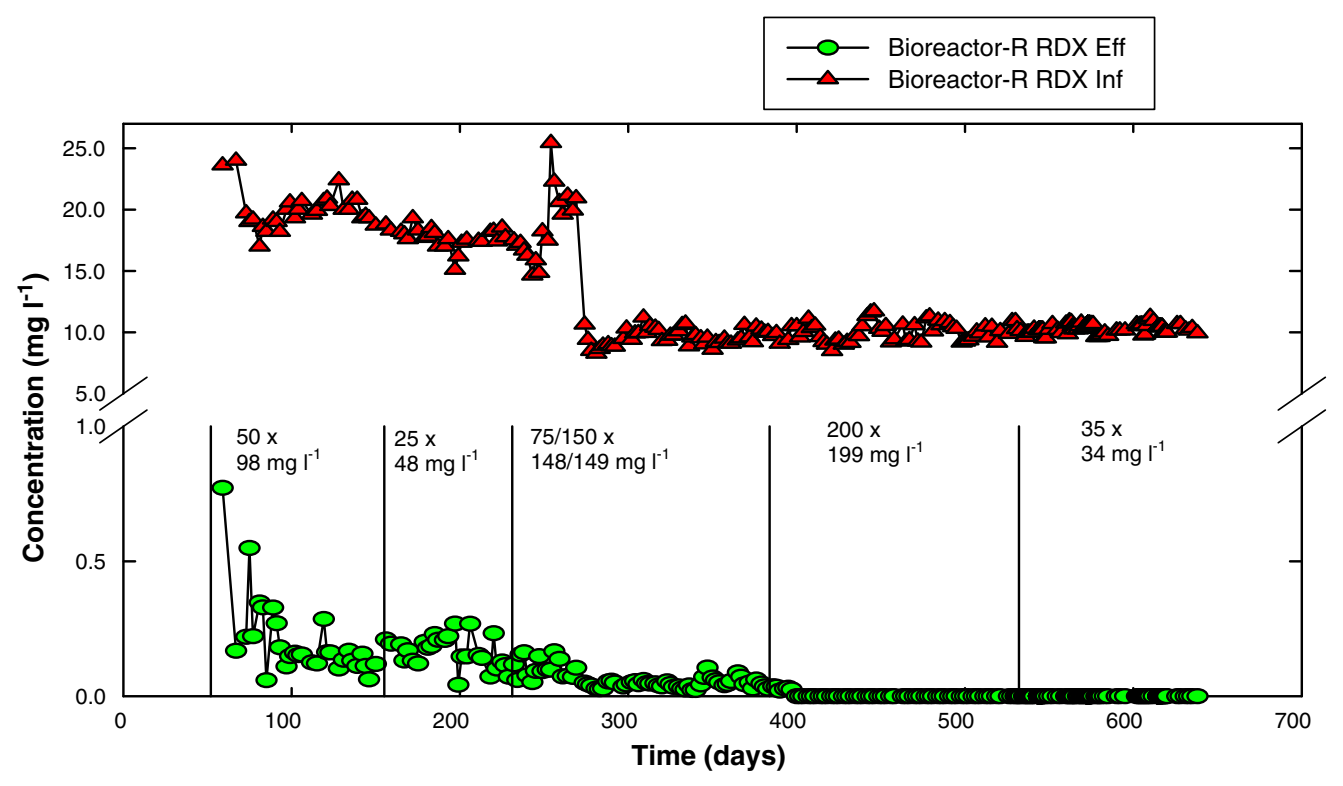

Fig. 3. Bioreactor-R RDX removal.

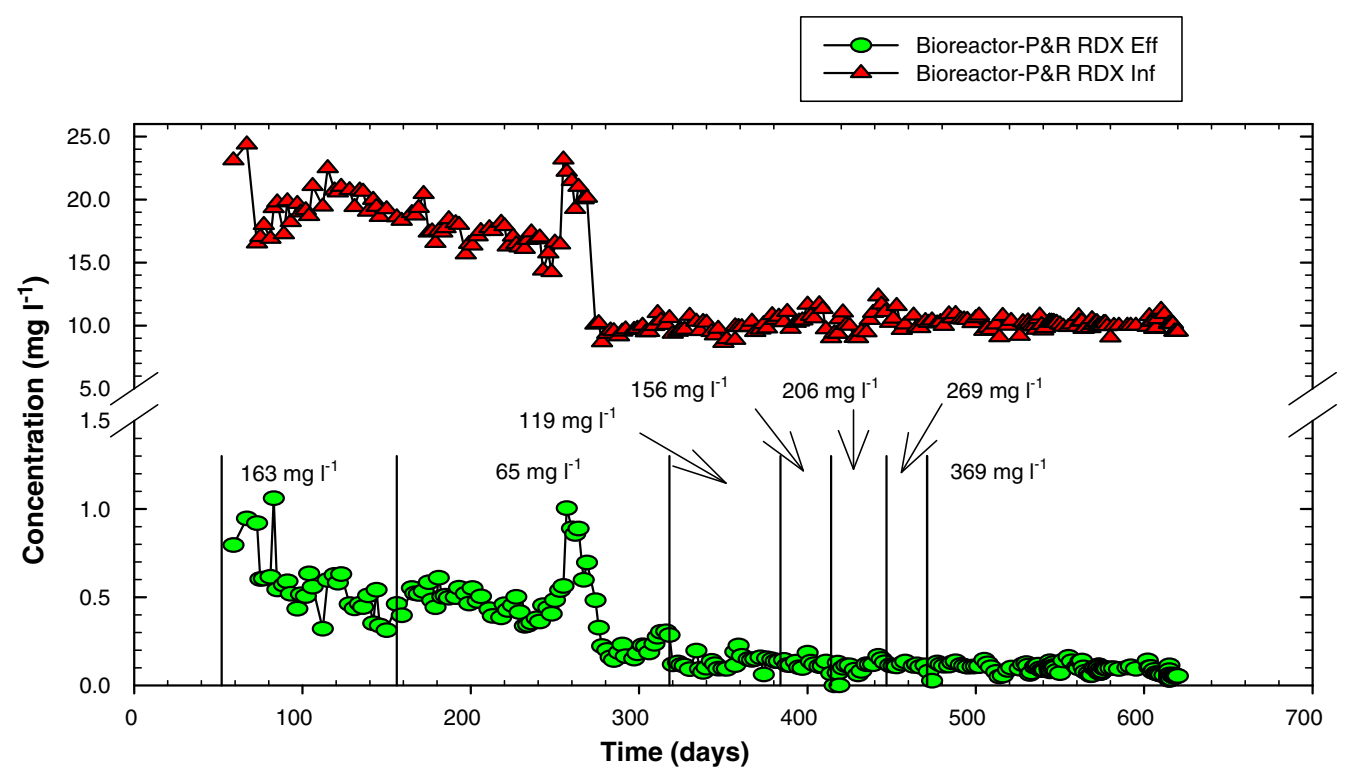

Fig. 4. Bioreactor-P RDX removal. 
during the first $100 \mathrm{~d}$ of operation of Bioreactor- $\mathrm{R}$, the feed concentration of ethanol was set to 50 times the required stoichiometric amount. During this period, the concentration of RDX in the effluent from this bioreactor gradually decreased from $\sim 800$ to $\sim 200 \mathrm{Mg} \mathrm{l}^{-1}$.

After steady-state operation was established, the feed ethanol concentration was reduced to 25 times the required stoichiometric amount on day 156. Due to this drop in ethanol, the concentration of RDX increased to $\sim 300 \mu \mathrm{g} \mathrm{l}^{-1}$, after which the concentration of ethanol was raised to 75 times the stoichiometric demand (day 232). On day 274 , the concentration of RDX in the feed was reduced from 20 to $10 \mathrm{mg} \mathrm{l}^{-1}$. This resulted in a sharp drop in the concentration of RDX in the effluent from $\sim 200$ to below $100 \mu \mathrm{gl}^{-1}$.

The bioreactor was run under these ethanol conditions for approximately $100 \mathrm{~d}$ with the concentration of RDX remaining at the same level. On day 385, the concentration of electron donor was increased to 200 times its stoichiometric amount with the corresponding concentration of RDX in the final effluent decreasing to below the detection limit.

The performance of Bioreactor-P\&R relative to RDX removal in shown in Fig. 4. This graph shows that, during the first $100 \mathrm{~d}$ of operation of this bioreactor, a pronounced variability was observed in effluent RDX concentrations. Nevertheless, during the period extending from days 100 to 156 , the effluent RDX concentration started to stabilize in the neighborhood of $500 \mu \mathrm{g} \mathrm{l^{-1 }}$.

On day 156, the influent ethanol concentration was reduced to 2.5 the stoichiometric demand, which resulted in a gradual decrease of effluent RDX concentration (from 500 to $350 \mu \mathrm{g} \mathrm{l}^{-1}$ ). Right after ethanol reduction, the concentration of RDX in the effluent remained at approximately $500 \mu \mathrm{gl}^{-1}$, but as the microbial consortia started adapting to the lower electron donor conditions, a gradual drop in the effluent RDX was observed.

On day 250, the concentration of RDX in the effluent increased from $\sim 300$ to $\sim 1000 \mu \mathrm{g} \mathrm{l}^{-1}$. This sharp increase in the effluent RDX concentration corresponded to an error in feed preparation that resulted in an influent RDX concentration of $24 \mathrm{mg} \mathrm{l}^{-1}$. On day 274 , the concentration of RDX in the influent to Bioreactor-P\&R was decreased from the target 20 to $10 \mathrm{mg} \mathrm{l}^{-1}$, which resulted in a decrease in the effluent RDX concentrations to approximately $200 \mu \mathrm{g} \mathrm{l}^{-1}$. When the influent ethanol concentration was increased to 3.9 times of its stoichiometric amount (day 319), another drop in the effluent concentration of RDX was observed. Under these conditions, the effluent RDX concentration stabilized at $100 \mu \mathrm{gl}^{-1}$, and even when the ethanol was raised four more times (to 4.9, 6.23, 7.9 and 10.5 times its stoichiometric amount) the concentration of RDX in the final effluent did not go below this level. Excess ethanol concentrations are represented in Figs. 3 and 4 in $\mathrm{mg} \mathrm{l}^{-1}$.

\section{Conclusions}

Perchlorate and RDX are two compounds that have been used extensively by the US military. Usage of these toxic compounds led to their transfer to the natural environment. Recent proposed formulations for insensitive munitions has led to the use of these materials in combination, which has never been done before. The current method for removal of RDX from wastewater is carbon adsorption, but carbon adsorption would be ineffective against a polar compound such as perchlorate. The most common method for removal of perchlorate is biodegradation, but anaerobic biodegradation of RDX is still an emerging technology, and has never been tested in combination with perchlorate at the high concentrations expected in wastewater. This study has shown that biological treatment with the employment of AFBRs represents a good alter- native for effective removal of perchlorate and RDX from the wastewater. Results from this study showed that the biodegradation of perchlorate and RDX is dependent on the concentrations of electron donor, ethanol, added to the bioreactors. Perchlorate seemed to require a lower dosage of electron donor (relative to stoichiometric requirements) to be reduced from the high influent concentration levels used in this study. Higher relative concentrations of ethanol were needed to achieve effective reduction of RDX. Biodegradation seemed to be greater in the bioreactors containing individual contaminants rather than the bioreactors where both contaminants were commingled. This demonstrates a competition between RDX and perchlorate in anaerobic treatment processes which must be taken into account for testing and design of larger scale facilities.

\section{Acknowledgments}

This research was supported by Engineering Research and Development Center - Construction Engineering Research Laboratory. They were also providers of the RDX. In addition, we would like to acknowledge Joint Munitions Command - Rock Island Arsenal.

\section{References}

Adrian, N.R., Arnett, C.M., 2004. Anaerobic biodegradation of hexahydro-1,3,5trinitro-1,3,5-triazine (RDX) by Acetobacterium malicum strain HAAP-1 isolated form a methanogenic mixed culture. Curr. Microbiol. 48, 332-340.

Aken, B.V., Yoon, J.M., Schnoor, J.L., 2004. Biodegradation of nitro-substituted explosives 2,4,6-trinitrotoluene, hexahydro-1,3,5-triazine and octahydro1,3,5,7-tetranitro-1,3,5-tetrazocine by a pythosymbiotic Methylobacterium sp. associated with poplar tissues (Populus deltoids x nigra DN34). Appl. Environ. Microbiol. 70, 508-517.

Atikovic, E., 2006. Anaerobic Treatment of Army Ammunition Production Wastewater Containing Perchlorate and RDX. M.S. Thesis, University of Cincinnati.

Cheng, J., Kango, Y., Suidan, M.T., Venosa, A.D., 1996. Anaerobic biotransformation of 2,4-dinitrotoluene: it's effect on the pathway of microbial utilization of ethanol. Water Res. 30, 307-314.

Fuller, M.E., Hatzinger, P.B., Condee, C.W., Togna, A.P., 2007. Combined treatment of perchlorate and RDX in groundwater using fluidized bed reactor. Ground Water Monitor. Remed. 27, 59-64.

Hautman, D.P., Munch, D.J., Eaton, A.D., Haghani, A.W., 1999. Method 314.0 Determination of Perchlorate in Drinking Water Using Ion Chromatography. USEPA, Washington, DC, SW-846.

Lewis, T.A., Ederer, M.M., Crawford, R.L., Crawford, D.L., 1977. Microbial transformation of 2,4,6-trinitrotoluene. J. Ind. Microbiol. Biotechnol. 18 89-96.

Luca, L.L., Cozzi, F., Germinias, G., 1999. Combustion mechanisms of an RDX-Based composite propellant. Combust. Flame 118, 248-261.

Maloney, S.W., Adrian, N.R., Hickey, R.F., Heine, R.L., 2002. Anaerobic treatment of pinkwater in a fluidized bed reactor containing GAC. J. Hazard. Mater. 92, 7788.

Parette, R., Cannon, F.S., Weeks, K., 2005. Removing low ppb level perchlorate, RDX and HMX from groundwater with cetyltrimethylammonium chloride (CTAC) pre-loaded activated carbon. Water Res. 39, 4683-4692.

Simplot, J.R., 1995. Ex-situ anaerobic bioremediation technology TNT for treatment of contaminated soils. Superfund Innovative Technology Evaluation, USEPA Washington, DC

Urbansky, E.T., 2000. Perchlorate in the Environment. Kluwer Academic, New York. USDD, 2003. Mineralization of TNT, RDX and their by-products in an anaerobic granular activated carbon-fluidized bed reactor. Environmental Security Technology Certification Program Department of Defense, DoD, Washington, DC.

USEPA, 1994. Method 8330 nitroaromatics and nitramines by high performance liquid chromatography (HPLC). In: USEPA, Washington, DC. Test Methods for Evaluating Solid Waste, Physical/Chemical Methods.

VanderLoop, S.L., Suidan, M.T., Motaleb, M.A., Maloney, S.W., 1998. Two-stage biotransformation of 2,4,6-trinitrotoluene under nitrogen-rich and nitrogenlimiting conditions. Water Environ. Res. 70, 189-196.

Veenstra, S.C., Weeks, K.R., Hill, D.L., Togna, A.P., 2003. Streamlined treatment option for remediation of commingled perchlorate and explosives in groundwater. In: National Defense Industrial Association (Ed.) 29th Environmental and Energy Symposium and Exhibition, Richmond, VA. 